\title{
Transliteration and Documentation
}

THE transliteration system employed here is designed for the convenience of non-Russian readers. Hence, the aim was to approximate the Russian sounds without diacritical marks, superscripts, or apostrophes.

The following transliteration table applies except for certain names such as Alexander or Moscow which are more recognizable in the traditional variation. Names of foreign origin such as Ehrenburg or Johansen are rendered in the version of the country of origin.

$\begin{array}{ll}\text { a } & \text { a } \\ \text { 6 } & \text { b } \\ \text { B } & \text { v } \\ \text { r } & \text { g } \\ \text { д } & \text { d } \\ \text { e } & \text { e } \\ \text { e } & \text { yo } \\ \text { X } & \text { zh } \\ \text { 3 } & \text { z } \\ \text { и } & \text { i } \\ \text { म } & \text { i }\end{array}$

$\begin{array}{ll}\mathbf{k} & \mathbf{k} \\ \mathbf{I} & \mathbf{1} \\ \mathbf{M} & \mathbf{m} \\ \mathbf{H} & \mathbf{n} \\ \mathbf{o} & \mathbf{0} \\ \mathbf{I} & \mathbf{p} \\ \mathbf{p} & \mathbf{r} \\ \mathbf{c} & \mathrm{s} \\ \mathbf{r} & \mathbf{t} \\ \mathbf{y} & \mathbf{u} \\ \mathbf{\phi} & \mathrm{f}\end{array}$

$\begin{array}{ll}\mathbf{x} & \text { kh } \\ \text { I } & \text { ts } \\ \text { Y } & \text { ch } \\ \text { w } & \text { sh } \\ \text { щ } & \text { shch } \\ \text { b } & \text { [omit] } \\ \text { b } & \text { y } \\ \text { b } & \text { [omit] } \\ \text { э } & \text { e } \\ \text { ю } & \text { yu } \\ \text { я } & \text { ya }\end{array}$

The works illustrated in this volume come mainly from three sources. The first segment of the book (Chapters I and II), showing the development of official Soviet art, uses reproductions from official sources. Dimensions, medium used, and the year when the work was painted, were not always given, and hence are not included in the text. The illustrations in the following chapters come in part from photographs taken by the authors in the homes and studios of the artists. Descriptions here, too, are sketchy. However, works in the possession of the authors and various collectors are fully documented, and credit lines appear in the picture legends. Unfortunately, certain photographs taken under difficult conditions in the Soviet Union make the works appear slightly out of square. 